\title{
Chemical defense among hydroids on pelagic Sargassum: predator deterrence and absorption of solar UV radiation by secondary metabolites
}

\author{
John J. Stachowicz*, Niels Lindquist \\ University of North Carolina at Chapel Hill, Institute of Marine Sciences, Morehead City, North Carolina 28557, USA
}

\begin{abstract}
The pelagic Sargassum community of the western Atlantic Ocean is species rich, with high densities of predatory fishes and invertebrates living in close association with the floating seaweed. Little, however, is known about predator-prey interactions among Sargassum inhabitants and the factors that might help maintain this species richness. To assess how predators may affect the abundance of sessile Sargassum epiphytes, and how these epiphytes may defend themselves against predators, we examined interactions between the most abundant small predator associated with Sargassum mats, the filefish Monacanthus hispidus, and 4 epuphytic hydroid species. This fish was the only Sargassum-associated predator to significantly consume hydroids in intial assays. When filefish were given a simultaneous choice of all 4 hydroid species, they consumed 40 to $45 \%$ of 3 species (Clytia noliformis, Aglaophenia latecarinata, and Tridentata turbinata), but consumed less than $5 \%$ of the fourth species, Tridentata marginata. Filefish consistently rejected small portions of $T$. marginata colonies, but consumed a palatable control food. Bioassay-guided fractionation of $T$. marginata extract resulted in the isolation of a single deterrent secondary metabolite, tridentatol A. Three additional metabolites (tridentatols $B$ to D) had no effect on filefish feeding. In addition to the defensive role of tridentatol A, the tridentatols ( $A$ to D) strongly absorb damaging solar ultraviolet (UV) radiation, and thus may function as sunscreens. To our knowledge, this is the first demonstration of chemical defenses among the pelagic Sargassum fauna, and the first report that a hydroid secondary metabolite deters consumers. Prey chemical defenses are an important factor in maintaining species richness in many predator-rich communities, but despite being chemically defended from predators, $T$. marginata was far less abundant than any of the other, more palatable, hydroids. The factors that allow highpreference hydroids to persist in such a predator-rich community remain unknown.
\end{abstract}

KEY WORDS: Chemical defense Filefish Hydroids - Predation - Sargassum - UV-sunscreen

\section{INTRODUCTION}

Chemical defenses protect many marine plants and invertebrates from potential consumers and are likely to play an important role in maintaining high biological diversity in habitats such as coral reefs where consumer activity is high (Hay 1985, 1996, Paul 1992, Pawlik 1993, Hay \& Fenical 1996). The pelagic Sargassum community of the North Atlantic is also species rich and can support high densities of predatory invertebrates and fishes (Dooley 1972, Bortone et al. 1977 .

•E-mail: jaystach@email.unc.edu
Butler et al. 1983, Coston-Clements et al. 1991, Settle 1993), but little is known about the factors that contribute to the high biological diversity of these floating algal communities. Although crypsis may protect small mobile crustaceans living on the Sargassum from predation (Hacker \& Madin 1991), chemical defenses could be common among sessile Sargassum epiphytes that lack cryptic coloration or obvious physical means to deter predators. Most research on Sargassum epifauna has focused on documenting patterns of species composition (e.g. Weis 1968, Fine 1970, Stoner \& Greening 1984, Calder 1995) rather than predatorprey interactions. Thus, critical information about the role of predators in structuring the epifaunal commu- 
nity is lacking Such studies also would form a foundation for examining the possible role of chemical defenses in epifaunal communities by identifying lowpreference prey.

Hydroids are typically the most abundant sessile epiphytes of pelagic Sargassum (Weis 1968, Morris \& Mogelberg 1973, Niermann 1986, Calder 1995) and may represent an important link between trophic levels. Despite their abundance, little is known about interactions between these Sargassum epiphytes and potential predators. As part of an effort to assess the importance of chemical defenses in predator-prey interactions in this community, we determined the susceptibility of 4 species of epiphytic hydroids to potential predators associated with floating Sargassum. Initial assays indicated that among predators commonly associated with pelagic Sargassum (e.g. crabs, shrimps, and fishes), only the filefish Monacanthus hispidus (L.) consumed significant quantities of hydroids. Prior studies reporting gut contents for $M$. hispidus associated with Sargassum confirm that they commonly consume hydroids in the field (Dooley 1972). The goal of this investigation is to examine the palatability of common epiphytic hydroids to $M$. hispidus, and investigate any low-preference hydroids for chemical defenses.

\section{METHODS}

Study organisms. The colonial thecate hydroids Clytia noliformis (Auct.), Aglaophenia latecarinata (Allman), Tridentata turbinata (Lamouroux), and Tridentata marginata (Kirchenpauer) have circumglobal distributions and are common epiphytes on pelagic Sargassum in the western Atlantic [Burkenroad (in Parr 1939), Morris \& Mogelberg 1973, Calder 1991, 1995]. We collected these 4 species from floating Sargassum plants off the coast of North Carolina, USA, near $34^{\circ} 10^{\prime} \mathrm{N}, 76^{\circ} 13^{\prime} \mathrm{W}$ Because these hydroids also occur in benthic habitats (Calder 1991, 1993), and because factors such as predation and UV-light levels may differ between pelagic and benthic habitats, we also collected benthic $T$ marginata from attached Sargassum filapendula, gorgonian skeletons, and bare rock at 2 to $4 \mathrm{~m}$ depth on Radio Island Jetty $\left(34^{\circ} 42^{\prime} \mathrm{N}\right.$, $76^{\circ} 41^{\prime} \mathrm{W}$ ) near Beaufort, North Carolina, so that we could compare the chemistry of pelagic and benthic populations of this hydroid. Polyps of these hydroids are encased by a chitinous skeletal material. Although nematocyst descriptions are unavailable for most thecate hydroids, microbasic mastigiophores, a type of nematocyst thought to defend corals (Wellington 1980), are present in C. noliformis (Ostman et al. 1987) and are common among hydroids in the families to which the other 3 species belong (Boullon 1985). C. noliformis grows as a single poly $\mathrm{p}$ borne on a stalk 0.8 to $2.8 \mathrm{~mm}$ high. A. latecarinata, $T$ turbinata, and $T$ marginata on pelagic Sargassum have upright stalks 10 to $20 \mathrm{~mm}$ high with polyps borne along a main stem ( $T$. turbinata), on side branches (A. latecarinata), or both ( $T$ marginata). Benthic $T$. marginata is morphologically similar to pelagic colonies, but larger (up to $50 \mathrm{~mm}$ length). All 4 species spread vegetatively via a stoloniferous network attached to the substrate. Hydroid nomenclature follows that of Calder (1991).

Numerous potential predators are associated with floating Sargassum rafts. We chose to examine the susceptibility of hydroids to predation by the filefish Monacanthus hispidus, the decapod shrimp Leander tenuicornis, and crabs in the genus Portunus, because these species commonly occur at high densities in Sargassum patches (Fine 1970, Stoner \& Greening 1984; see 'Results', this study). Juvenile $M$. hispidus were the most abundant small predator in our survey of Sargassum epifauna (see 'Results'), and have been reported to be the most abundant fish associated with pelagic Sargassum in the Gulf Stream (Settle 1993), the Florida Current (Dooley 1972), and the northern Gulf of Mexico (Bortone et al. 1977). Hydroids are commonly found in the guts of these fish and appear to comprise the majority of the filefish diet, although copepods and barnacles supplement the diet in summer and winter. respectively (Dooley 1972). As late-stage juveniles (standard length $>50 \mathrm{~mm}$ ), these filefish emigrate from the Sargassum to benthic habitats (Berry \& Vogele 1961). Filefish used in laboratory feeding experiments ranged in size from 13 to $25 \mathrm{~mm}$ standard length. Relatively little is known about the small crustaceans that inhabit pelagic Sargassum, although Butler et al. (1983) reported that both portunid crabs and $L$. tenuicornis consume a wide array of plant and animal material including hydroids. Because juvenile portunid crabs can be very difficult to distinguish to the species level (crabs we used ranged in size from 5 to $12 \mathrm{~mm}$ carapace width), our assays used a mixed species group of crabs in the genus Portunus. L. tenuicornis used in these assays ranged in carapace length from 9 to $26 \mathrm{~mm}$.

Abundance surveys. Our study site was located about 30 nautical miles $(55 \mathrm{~km}$ ) southeast of Cape Lookout, North Carolina in the vicinity of $34^{\circ} 10^{\prime} \mathrm{N}$, $76^{\circ} 13^{\prime} \mathrm{W}$ To determine the abundance of the study organisms on pelagic Sargassum at this site, we collected clumps of the floating al.ga with a $500 \mu \mathrm{m}$ mesh net strung on a $1 \times 1 \mathrm{~m}$ frame. On the days these collections were made, the Sargassum was aggregated in fairly dense patches, and several individual plants were often captured in each sample. The entire clump of Sargassum, together with all associated animals, 
was placed in a large plastic bag and preserved in $10 \%$ formalin in seawater. At the laboratory, plants were rinsed vigorously in fresh water to remove the mobile fauna for counting, and the volume of Sargassum in each clump was measured by displacement of water in a 2 l graduated cylinder.

The plants were then spread out on a flat surface and 20 'leaflets' (leaf-like blades) were randomly selected and removed for quantification of hydroid biomass. The stalks of each species on each leaflet were counted under a dissecting scope at $10 \times$ magnification. Because the hydroids are small, their mass on a single leaflet was too low to be reliably measured. Instead, the average wet mass of a single hydroid stalk was estimated for each species by removing all the hydroids of a given species and weighing these to the nearest $0.1 \mathrm{mg}$. The mass of this clump of hydroids was then divided by the total number of stalks counted of that species, yielding an average mass per stalk. For each species, we estimated the mass of hydroids per leaflet by multiplying its average stalk mass by the number of stalks on each leaflet. The surface area of each leaflet was determined by averaging duplicate runs on a Li-Cor 300 area meter. These data were used to estimate hydroid mass per $\mathrm{cm}^{2}$ of leaflet area for each clump.

Whole-organism feeding assays. To determine the extent to which filefish and crustaceans might prey on hydroids, we offered the 4 species of hydroids to each of the 3 potential predators with no alternative foods available. For each species of hydroid, we removed 80 similarly sized Sargassum leaflets that were covered with an approximately equivalent amount of hydroids. We placed 1 leaflet in each of 80 plastic bowls with 200 to $250 \mathrm{ml}$ seawater. The bowls were arranged in 20 blocks of 4 bowls each. Within each block, we placed a filefish in the first bowl, a crab in the second bowl, a shrimp in the third bowl, and the fourth bowl served as our no-predator control. The actual arrangement of the treatments within each block was varied haphazardly. Recent work (Dethier et al. 1993) has shown that visual estimation of percent cover can be more accurate and more repeatable than a random point quadrat method. Additionally, because these hydroids probably would not survive in the lab for the extended period that would have been required to obtain percent cover estimates for all 320 Sargassum leaflets, we opted for a visual estimation of hydroid percent cover, thereby greatly reducing the time needed to set up and score the assay, and permitting greater replication. Visual estimation of hydroid cover (to the nearest $10 \%$ ) was aided by dividing each side of each leaflet into 5 equal sections, and noting the presence of hydroids in each section. After allowing predators to feed for $48 \mathrm{~h}$, we reassessed hydroid cover as before, and analyzed for significant differences in change in percent cover among hydroid species and the control for each predator using the non-parametric Kruskal-Wallis test. Multiple comparisons were made using methods set forth by Zar (1984). Occasionally, a consumer jumped out of its bowl and into a neighboring bowl; data from these replicates were discarded. Although visual estimates have been criticized in the past for their subjectivity, there could have been no observer bias in this assay because it was chronologically the first assay we performed, so the observer had no reason to bias the data toward consumption or avoidance of any particular hydroid by any of the predators.

Results of the previous assay indicated that the crustaceans avoided consuming hydroids, while filefish significantly reduced cover of 3 of the 4 hydroid species (see 'Results'). Therefore, we focused the remainder of our investigation on interactions between filefish and hydroids. To determine the relative palatability of the hydroids to the filefish, we offered 20 separate filefish a simultaneous choice of all 4 hydroid species. Because these hydroids are clonal, and adjacent leaflets are usually covered by stalks belonging to the same individual connected via a stoloniferous network, we assigned adjacent leaflets from the Sargassum plants to paired treatment and control replicates to minimize effects of individual variation in the assay results. We removed 20 pairs of adjacent leaflets densely covered with hydroids for each of the 4 species and placed leaflets from a pair in adjacent plastic bowls with 200 to $250 \mathrm{ml}$ of seawater. Thus, each bowl had 4 leaflets -1 for each of the 4 hydroid species. As an initial measure of hydroid abundance, we counted the number of hydroid stalks per leaflet for the 3 larger species (Aglaophenia latecarinata, Tridentata marginata and $T$. turbinata). However, individual stalks of Clytia noliformis are small and each leaflet contained numerous stalks, making the number of stalks per leaflet difficult to count reliably. Thus, for this species, we visually estimated change in percent cover to the nearest $10 \%$ using methods outlined previously. A filefish was added haphazardly to 1 bowl of each pair, and after $24 \mathrm{~h}$, we re-measured hydroid abundance as described previously.

Changes in hydroid abundance on control leaflets were used to correct changes in the filefish treatment to account for changes unrelated to filefish feeding (e.g. growth, senescence). This was done using the formula $D=\left[T_{\mathrm{i}}\left(C_{\mathrm{f}} / C_{\mathrm{i}}\right)-T_{\mathrm{f}}\right]$, where $T_{1}$ and $T_{\mathrm{f}}$, and $C_{\mathrm{i}}$ and $C_{1}$, are initial and final numbers, respectively, of hydroid stalks (or percent cover for Clytia noliformis) on leaflets in filefish treatment $(T)$ and controls $(C)$. For the 3 larger species for which stalk counts were made, $D$ was divided by $T_{1}$ to obtain the percent change in hydroid abundance. Changes in hydroid abundance 
on control leaflets were negligible $(<5 \%)$ and most did not change at all. Although within each bowl the initial number of hydroid stalks on each leaflet differed (with many more small $C$. noliformis per leaflet than any of the other 3 hydroids), the leaflet area occupied by the hydroids was similar for all species. Because the size of each leaflet was similar (ca $1.55 \mathrm{~cm}^{2}$ ), and the volume of the experimental arena was small, the frequency of filefish encounters with patches of each hydroid should have been high, and similar for all species.

Because each filefish was offered a simultaneous, and thus non-independent, choice of 4 species, changes in hydroid cover could not be compared statistically using ANOVA (Peterson \& Renaud 1989). Instead, we ranked consumption of the hydroids within each replicate and analyzed for significant differences using the non-parametric Friedman test which does not require independence between treatments (Conover 1980). Multiple comparisons were made using Friedman's multiple comparisons test (Conover 1980) and adjustments to the significance level made using the DunnSidak method (Sokal \& Rohlf 1981).

Thus far we have assayed whether predators consume hydroids either (1) when no alternative food is available, or (2) when only other hydroids are available. But in order to determine which hydroid species filefish might consume in the field, where other prey types may occur, we must compare the palatability of each hydroid species to a food that filefish would readily consume. Published gut contents data is inadequate for this purpose because it does not distinguish between different hydroid species (e.g. Dooley 1972, Butler et al. 1983). Therefore, we offered fish ( $n=11$ to 13) bite-sized portions of each hydroid followed by a brine shrimp (Artemia nauplii, our palatable control food). Foods were presented in this order to ensure that the filefish were not satiated if they rejected a hydroid piece, and because in preliminary assays filefish would sometimes not sample the hydroid if offered a brine shrimp first. Filefish were fed brine shrimp approximately $1 \mathrm{~h}$ before the assay to confirm their willingness to feed. Fisher's exact test was used to determine significant differences in consumption of each hydroid versus the brine shrimp control.

In the choice and no-choice assays filefish consistently consumed 3 of the hydroids (Clytia noliformis, Aglaophenia latecarinata, and Tridentata turbinata), but avoided the fourth, $T$. marginata. Because T. marginata was morphologically similar to the other species in size, shape, and skeletal construction, and was always rejected when compared to a palatable control food (see 'Results'), we hypothesized that this animal is chemically defended. To test this hypothesis, we compared filefish consumption of a palatable squid-based food versus their consumption of an equivalent food containing natural volumetric concentrations of crude lipophilic or water-soluble T. marginata extract.

Extraction procedure. Prior to extracting Tridentata marginata stalks removed from Sargassum leaflets, we measured the displacement volume and wet mass of a pooled collection of the stalks after blotting them dry on a paper towel. The fresh hydroid was extracted 3 times with $25 \mathrm{ml}$ of 2:1 dichloromethane (DCM)/ methanol (MeOH), followed by extraction with $25 \mathrm{ml}$ of water Solvents were removed from the pooled DCM/ $\mathrm{MeOH}$ extracts by rotary evaporation. To thoroughly separate lipophilic from water-soluble compounds, the dried DCM/MeOH extract was partitioned between DCM $(50 \mathrm{ml})$ and water $(25 \mathrm{ml}$ of water-soluble extract + additional $25 \mathrm{ml}$ distilled water). After mixing in a separatory funnel, the DCM and water separated into 2 distinct layers. The heavier DCM layer was drained off and concentrated by rotary evaporation. The water-soluble extract was frozen and lyophilized. The lipophilic and water-soluble extracts were stored at $-70^{\circ} \mathrm{C}$. Ten percent of these extracts was set aside for later chemical analysis by high performance liquid chromatography (HPLC).

Bioassay-guided fractionation. The palatable assay food was made by pureeing squid mantle flesh with an equal volume of distilled water and sodium alginate at $2 \%$ of total wet mass. To make the treatment foods, the amount of extract from $100 \mu \mathrm{l}$ of hydroid tissue was transferred to a glass vial and dried under a slow stream of nitrogen $\left(\mathrm{N}_{2}\right)$ gas. $\mathrm{DCM}$ was used to dissolve and transfer the lipophilic compounds, and water was used with the water-soluble compounds. Squid paste was mixed directly into the dried water-soluble material using a spatula; however, to evenly disperse the lipophilic compounds into the squid paste, $2 \mu \mathrm{l}$ of ethanol was added first to solubilize this material, then $100 \mu \mathrm{l}$ of squid paste was mixed into it using a spatula. An equivalent amount of ethanol was added to the control food for assays testing lipophilic metabolites. To form the treatment and control food pellets, the squid paste/extract mixture was spread into a thin film approximately $1 \mathrm{~mm}$ thick and covered with a $0.25 \mathrm{M}$ calcium chloride solution which caused the squid paste to harden to the consistency of cooked pasta. Both treatment and control pellets were made by cutting the solidified food into square pellets, each having a volume of 2 to $3 \mu \mathrm{l}$. We first offered fish a control pellet; if it was consumed, we then offered the fish a treatment pellet and recorded if it was consumed or rejected. If the treatment pellet was rejected, we then offered the fish a second control pellet to determine if the fish possibly rejected the treatment pellet because it was satiated. Fish rejected this second pellet in only 3 of 122 replicates; these replicates were dropped from the analysis. We used Fisher's exact test to determine sig- 
nificant differences in filefish consumption of treatment versus control food pellets. Sample sizes for assays testing the water-soluble and lipophilic compounds were 13 and 15 , respectively.

Feeding assays with the crude water-soluble and lipophilic extracts of Tridentata marginata showed that only the lipophilic material significantly decreased filefish feeding (see 'Results'). Bioassay-guided fractionation of the lipophilic extract was used to isolate the deterrent metabolite(s). Initial fractionation of the lipophilic crude extract was accomplished by thicklayer chromatography. After applying the extract to a silica-gel plate $(20 \times 20 \mathrm{~cm} \times 1 \mathrm{~mm}$ thick $)$, the plate was sequentially developed with the following solvents (1) hexanes; (2) 3:1 hexanes/diethyl ether (hereafter called ether); (3) 1:1 hexanes/ether; (4) ether; and (5) $85: 15 \mathrm{DCM} / \mathrm{MeOH}$. We allowed developing solvents $1,2,3$, and 5 to run halfway up the plate, and 4 to run the entire height of the plate. This procedure distributed compounds into discrete bands from the origin to the top of the plate. We divided these bands into 5 nearly equally sized regions, and carefully scraped the silica within each region of the glass backing using a razor blade. Compounds were extracted from the silica by washing it 3 times with $5 \mathrm{ml}$ of $2: 1 \mathrm{DCM} / \mathrm{MeOH}$. Compounds in fractions 1 (the least polar material at the top of the plate) through 5 (the most polar material at the bottom of the plate) were tested for deterrent effects on filefish feeding at their natural volumetric concentrations as described above.

Only fraction 2 significantly deterred feeding by filefish (see 'Results'). The UV-fluorescent indicator on the silica-gel plate (which glows purple when illuminated with $254 \mathrm{~nm}$ UV light in the presence of a UV-absorbing compound) showed that fraction 2 contained a metabolite that had a UV-absorbing chromophore. This UV-absorbing band was easily separated from the rest of fraction 2 using another thick layer silica-gel plate developed with 3:1 hexanes/ether, and was assayed for feeding deterrent properties as described previously.

This UV-absorbing band was the only deterrent material in fraction 2 (see 'Results'). Final purification of compounds was accomplished by an HPLC system consisting of a Beckman $100 \mathrm{~B}$ solvent delivery module, a $100 \mu \mathrm{l}$ sample loop, a $4.6 \times 100 \mathrm{~mm}$ silica column (Si80-11-C3, Rainin Instruments, Inc.), a Spectra Physics SP8780 autosampler, a Spectra Physics SP8430 Refractive Index (RI) detector, and a Waters 996 photo-diode array (PDA) detector (Millipore Corp.), with an eluting solvent of $8.5 \%$ ethyl acetate in iso-octane delivered at $0.85 \mathrm{ml} \mathrm{min}{ }^{-1}$ The deterrent fraction contained only 2 compounds, both novel, which we named tridentatol A and tridentatol B (Fig. 1). These compounds were assayed individually for their effects on filefish

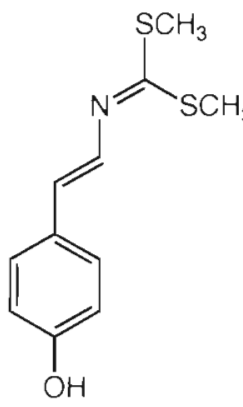

A

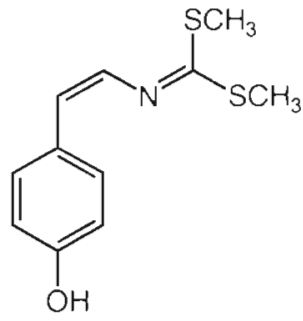

B<smiles>CSc1ncc(-c2ccc(O)cc2)s1</smiles>

C
Fig. 1. Structures of the tridentatols

feeding. To examine the relationship between a compound's structure and its activity in our feeding assay, we also tested a third related compound (tridentatol C, Fig. 1) isolated from thick-plate fraction 4 by HPLC using $15 \%$ ethyl acetate/iso-octane as the eluting solvent. The structures of tridentatols $\mathrm{A}$ and $\mathrm{B}$ were determined by spectral comparison $\left({ }^{1} \mathrm{H}\right.$ NMR, ${ }^{13} \mathrm{C}$ NMR, UV, IR) with data for tridentatol $C$, the structure of which was determined by single crystal X-ray diffraction analysis (Lindquist et al. 1996).

We used the purified compounds to generate standard curves of RI detector response versus compound concentration. For each compound, the concentration for 5 standard solutions showed a strong linear correlation with peak area $\left(r^{2}>0.974\right.$ for each compound) and bracketed solution concentrations encountered during the analysis of the crude lipophilic extract. Peak areas from each standard and each tridentatol from the lipophilic crude extract were averaged from duplicate $20 \mu \mathrm{l}$ injections. Eluting solvents and flow rates for the analytical runs were as described above.

To determine the relationship between natural concentrations of the tridentatols and the amount of compound needed to deter filefish feeding, we also tested tridentatol $\mathrm{A}$ at $65,32,13$, and $6.5 \%$ of its natural concentration $\left(7.8 \mathrm{mg} \mathrm{ml}^{-1}\right.$, see 'Results'), and tridentatols $\mathrm{B}$ and $\mathrm{C}$ at 350 and $300 \%$, respectively, of their natural concentrations (1.4 and $1.7 \mathrm{mg} \mathrm{ml}^{-1}$, respectively; see 'Results'). Although individual metabolites may or may not deter consumers, combinations of these metabolites could have effects on consumers that are missed in assays of single compounds. To test for interactive effects of the tridentatols, we added $0.5 \mathrm{mg} \mathrm{ml}^{-1}$ of the non-deterrent metabolites tridentatol $\mathrm{B}$ or $\mathrm{C}$ to $0.5 \mathrm{mg}$ $\mathrm{ml}^{-1}$ of tridentatol $\mathrm{A}$ (the highest concentration tested that did not deter filefish feeding, see 'Results'). This brought the total tridentatol concentration to $1.0 \mathrm{mg}$ $\mathrm{ml}^{-1}$, equal to the amount of tridentatol A alone needed to significantly reduce filefish feeding (see 'Results'). Additionally, we tested a mixture of tridentatols $B$ and 
C, each added at $100 \%$ of natural concentration, for interactive effects on filefish feeding.

Because Monacanthus hispidus and Tridentata marginata also co-occur in benthic inshore habitats, we used a similar bioassay-guided methodology to examine the palatability of the crude extract from benthic $T$ marginata to filefish, allowing us to chemically compare pelagic versus benthic populations of this hydroid. We used analytical HPLC methods identical to those for pelagic $T$ marginata to determine the natural concentration of the tridentatols in the lipophilic crude extract of benthic $T$. marginata. Benthic $T$ marginata produces tridentatol $\mathrm{A}$, but not tridentatols $\mathrm{B}$ and $\mathrm{C}$. However, benthic $I$ marginata produces a different metabolite, tridentatol D (structure currently under investigation), which was similar in polarity to tridentatol C, and isolated using a separation protocol identical to that used for tridentatol $C$.

Alternative functions of the tridentatols. Schmitt et al. (1995) showed that secondary metabolites from marine algae could have multiple functions that are ecologically important (e.g deterring consumers and reducing fouling). Because living near the ocean surface exposes Sargassum inhabitants to high levels of solar UV radiation, and given that the tridentatols absorb UV radiation, we hypothesized that these compounds may act as sunscreens. To establish a foundation for this hypothesis, we determined if the tridentatols absorbed the wavelengths of solar UV radiation (290 to $400 \mathrm{~nm}$ ) thought to be biologically damaging. Tridentatols $A$ to $D$ were each dissolved in methanol at a concentration of $0.01 \mathrm{mg} \mathrm{ml}^{-1}$. One $\mathrm{ml}$ of this solution was injected directly into the PDA, which was programmed to measure UV absorption from 290 to $400 \mathrm{~nm}$. At the wavelength of maximum UV absorption $\left(\lambda_{\text {max }}\right)$, the molar extinction coefficient $(\varepsilon$, a measure of per molecule UV-absorbing power) was calculated for tridentatols $\mathrm{A}$ to $\mathrm{C}$ using the equation $\varepsilon=A /(b \times c)$ where $A$ is the measured absorption at $\lambda_{\max }, b$ is the path length of the PDA flow cell, and $c$ is the molar solution concentration of the compound. The value of $\varepsilon$ for tridentatol $D$ could not be determined because its molecular weight has not yet been determined. The UV spectrum of the water-soluble compounds from Tridentata marginata was also recorded to determine if any other UV-A- or UV-B-absorbing compounds were present in this animal.

To further evaluate the potential of the tridentatols to function as UV screens, their spectra were compared to the 290 to $400 \mathrm{~nm}$ spectra of the 4 'active ingredients' coctyl methoxy-cinnamate, benzophenone, octocrylene, and octyl salicylate) from Coppertone ${ }^{(}$SPF 45 sunscreen. These compounds were isolated by extraction. of $5 \mathrm{ml}$ of the sunscreen with DCM, flash chromatography of the DCM-soluble portion of the sunscreen over silica gel using hexanes/diethyl ether mixtures as elutents, and final purification by silica HPLC. Spectra were obtained in methanol at concentrations of $0.01 \mathrm{mg} \mathrm{ml}^{-1}$ as described previously for the tridentatols.

\section{RESULTS}

\section{Abundance of experimental organisms}

Among the mobile fauna examined, only filefish were observed to evade our sampling gear; this occurred primarily when sampling Sargassum patches larger than our net, as some filefish would swim to plants outside the reach of the net. Despite the fact that we underestimated their abundance, filefish were still the most abundant of the potential hydroid predators At a density of $75.3 \pm 14.0$ ind. $1^{-1}$ of Sargassum (mean $\pm 1 \mathrm{SE}$ ), filefish were at least 3 times more abundant than any predatory invertebrate in our samples (crabs, shrimps, nudibranchs). Hydroid abundance (wet mass per unit surface area) also differed by species (Table 1; 1 -way ANOVA, $p<0.0001$ ). Multiple comparisons by Fisher's Protected Least Squares Difference (PLSD) test showed that Aglaophenia latecarinata and Clytia noliformis were significantly more abundant than Tridentata marginata (Table $1 ; p<0.05$ ), and that the abundance of $T$. turbinata did not differ significantly from that of $C$. noliformis or $T$ marginata.

Table 1. Abundance (mean $+1 \mathrm{SE}$ ) of hydroids on pelagic Sargassum patches sampled near the western wall of the Gulf Stream off Cape Lookout. North Carolina. Results of post ANOVA $\{F=7.205 ; \mathrm{p}<0.0001)$ multiple comparisons are given in the right-hand column; species marked with the same letters do not differ significantly in abundance $(p>$ 0.05). A total of 36 Sargassum clumps were sampled

\begin{tabular}{|lcc|}
\hline Species & $\begin{array}{c}\text { Hydrold abundance } \\
\text { (mg wet mass } \mathrm{cm}^{-2} \text { ) }\end{array}$ & $\begin{array}{c}\text { Fisher's } \\
\text { PLSD }\end{array}$ \\
\hline Aglaophenia latecarinata & $0.152 \pm 0.027$ & $\mathrm{~A}$ \\
Clytia noliformis & $0.104 \pm 0.029$ & $\mathrm{AB}$ \\
Tridentata turbinata & $0.063 \pm 0.018$ & $\mathrm{BC}$ \\
Tridentata marginata & $0.013 \pm 0.007$ & $\mathrm{C}$ \\
\hline
\end{tabular}

\section{Feeding assays}

Neither of the crustacean predators consumed significant amounts of any of the 4 hydroid species, while filefish consumed significant amounts of 3 species, but ignored the fourth, Tridentata marginata (Fig. 2A-D). When offered all 4 hydroids simultaneously, filefish had virtually no effect on the abundance of $T$ mar- 
Fig. 2. Changes in hydrold cover (mean $+1 \mathrm{SE}$ ) after $48 \mathrm{~h}$ exposure to various predators or a nopredator control for the hydroids (A) Aglaophenia latecarinata, (B) Clytia noliformss, (C) Tridentata turbinata, and (D) T. marginata. Analysis was by Kruskal-Wallis test with multiple comparisons. $\mathrm{n}$ is given at the base of each bar. Letters above each bar denote significant differences between species $(p<0.05)$
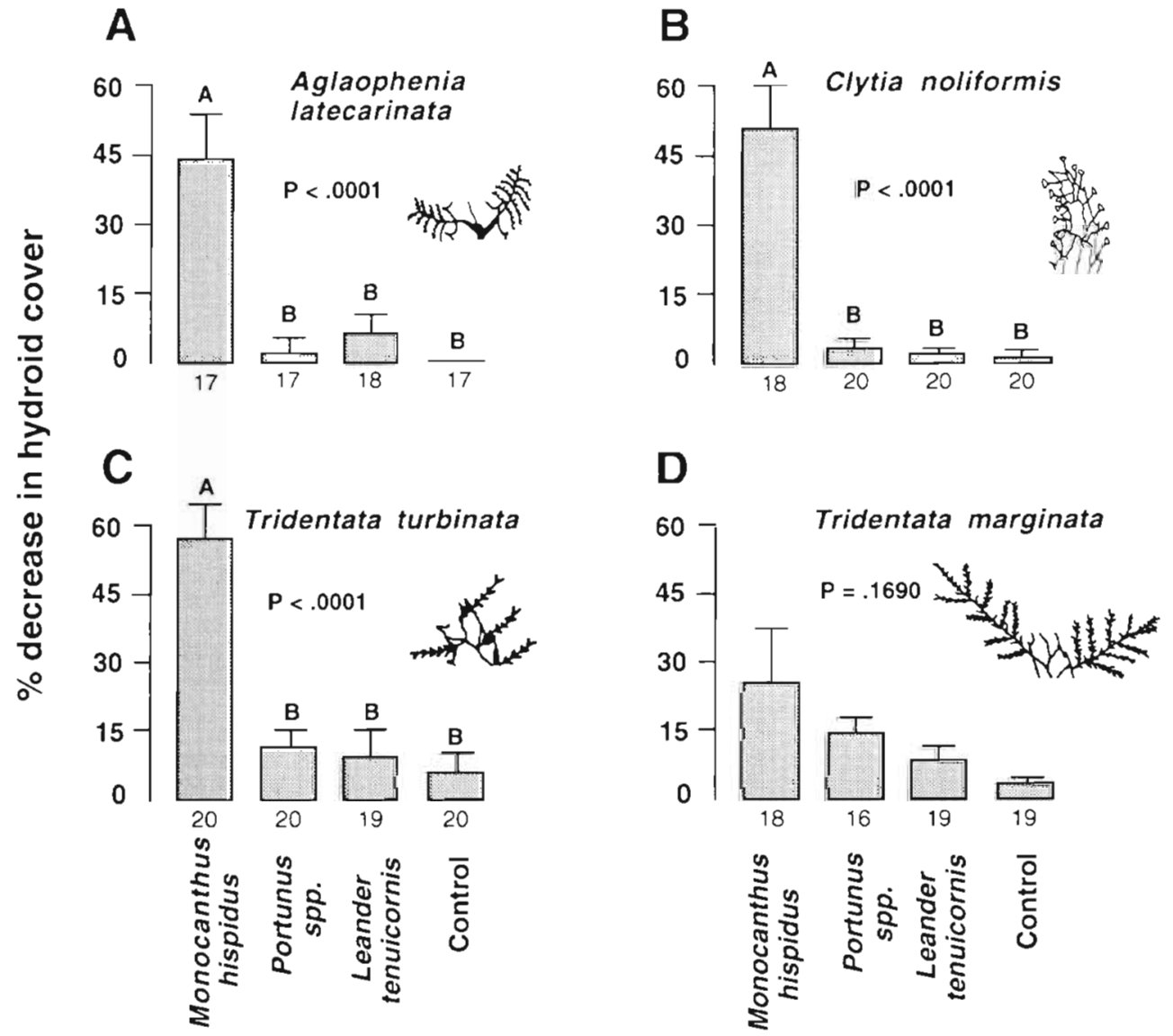

ginata ( $<5 \%$ decrease), while significantly reducing the abundance of the other 3 hydroids by 40 to $45 \%$ (Fig. 3; p $<0.05$, Friedman's test). When we compared filefish feeding on a bite-sized piece of each hydroid species with their consumption of brine shrimp, filefish ate Aglaophenia latecarinata and T. turbinata at levels not significantly different from those for brine shrimp (Fig. 4). However, filefish consumed significantly fewer portions of Clytia noliformis (-45\%) and T. marginata $(-90 \%)$ than brine shrimp (Fig. $4 ; \mathrm{p}=0.0186$ and $p<0.0001$, respectively). Filefish commonly mouthed the hydroid pieces, sometimes spitting out and recapturing them several times before ultimately ingesting or rejecting them. Because $C$. noliformis stalks bear only a single polyp, roughly the size of a brine shrimp, but less pigmented, filefish may have lost sight of the hydroid after spitting it out, because they appeared to continue searching for it. This may account for the significant difference in consumption of this hydroid versus brine shrimp despite the results of 2 previous assays suggesting that $C$. noliformis is readily consumed by filefish (Figs. $2 \& 3$ ).

The response of filefish to squid-based food pellets containing the crude lipophilic extract of Tridentata
Fig. 3. Filefish Monacanthus hispidus consumption of live hydronds: percentage of each species of hydroid (Clytia noliformis, Aglaophenia latecarinata, Tridentata turbinata, and $T$. marginata) consumed by filefish (mean $+1 \mathrm{SE}$ ) given a simultaneous choice between all 4 species. Analysis was by Friedman's multiple comparison test. Letters above each bar denote significant differences between species $(p<0.05)$ 


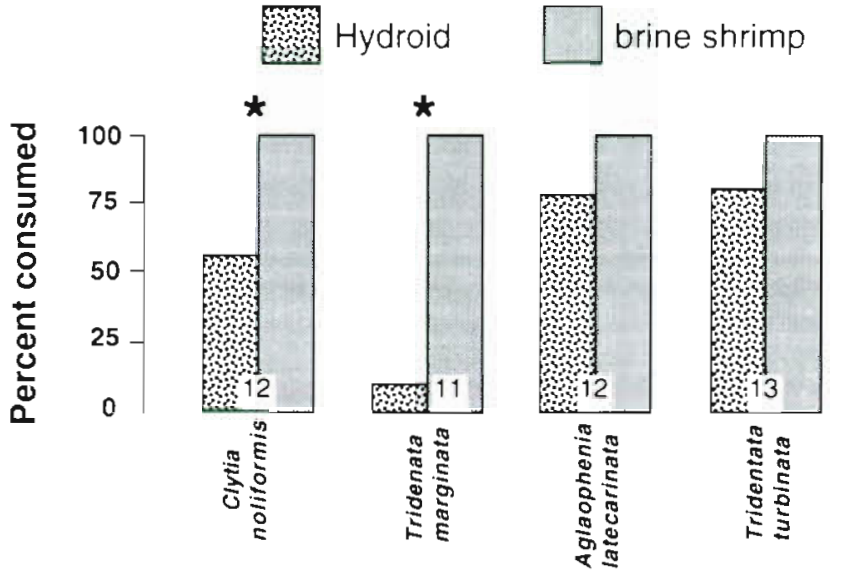

Fig 4 Percentage of hydrolds consumed relative to a palatable control (brine shrimp) Analysis was by Fisher's exact test * Significant differences $(p<005)$ in consumption between hydrold and control $n$ is given at the base of each bar

marginata demonstrated that this hydrold is chemucally unpalatable Although the crude water-soluble extract had no negative effect on filefish feeding, the crude lipid-soluble extract (= DCM-soluble) strongly reduced feeding by $87 \%$ (Fig 5A, p $<0.0001$, Fisher's exact test) Among the 5 lipid-soluble fractions collected from the sllica-gel thick plate, only fraction 2 signuficantly deterred fish feeding $(-87 \%$, Fig 5B; $p<$ 00001 , Fisher's exact test). Only the UV-absorbing band within fraction 2 significantly decreased filefish teeding $\left(-79 \%\right.$. Fig. $5 \mathrm{C}_{i} \mathrm{p}<0.0001$, Fisher's exact test) the remander of this fraction did not affect filefish feeding

HPLC analysis of this deterrent UV-absorbing band showed that it contained only 2 compounds (tridentatols A and B), both with similar UV spectra. Tridentatol A (Fig. 1) was the major metabolite in the deterrent UV-absorbing band. Its natural volumetric concentration was $7.8 \mathrm{mg} \mathrm{ml}^{-1}$ of hydroid tissue. Tridentatol A significantly deterred filefish feeding down to $13 \%$ $\left(1.0 \mathrm{mg} \mathrm{ml}^{-1}\right.$ ) of its natural concentration but not at $65 \%\left(0.5 \mathrm{mg} \mathrm{ml}^{-1}\right)$ of natural concentration (Fig. 6). The minor compound in the deterrent UV-band, tridentatol B (FIg 1), had no negative effect on filefish feeding at its natural concentration of $1.4 \mathrm{mg} \mathrm{ml}^{-1}$. Even at 3.5 tumes natural concentration $\left(5.0 \mathrm{mg} \mathrm{ml}^{-1}\right)$, tridentatol $B$ still had no significant impact on fish feeding (Fig 6). The natural volumetric concentration of tridentatol $\mathrm{C}$ was $1.7 \mathrm{mg} \mathrm{ml}^{-1}$ and, like tridentatol $\mathrm{B}$, tridentatol $C$ had no significant effect on fish feeding, even at 3.0 tımes $\left(5.1 \mathrm{mg} \mathrm{m}^{-1}\right)$ its natural concentration
A

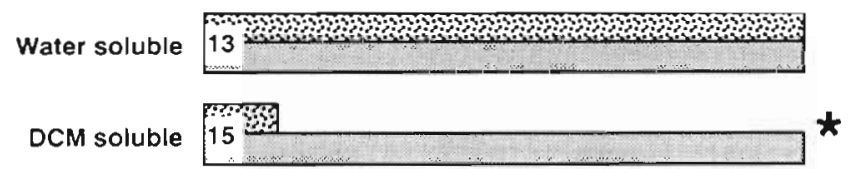

B

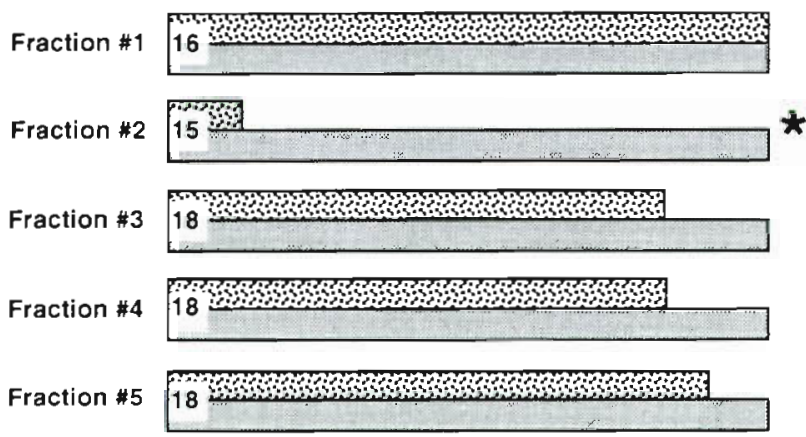

C

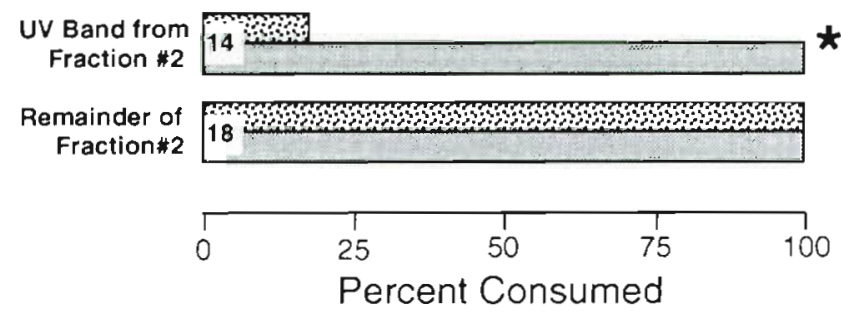

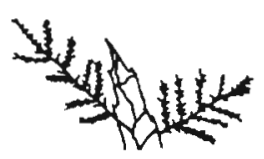

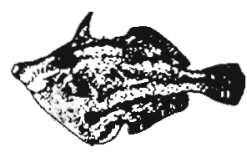

Flg 5 Filefish Monacanthus hispidus consumption of a palatable squid-based food with and without Tridentata marginata extracts. Data are expressed as the percentage of treatment and control foods consumed by filefish for (A) crude extracts and prep plate fractions; and $(B, C)$ components of the deterrent fraction from the lipophilic extract. Analysis was by Fisher's exact test. * Signifıcant differences $(p<0.05)$ in consumption between control pellets and pellets treated with hydroid extract. $n$ is given at the base of each bar 


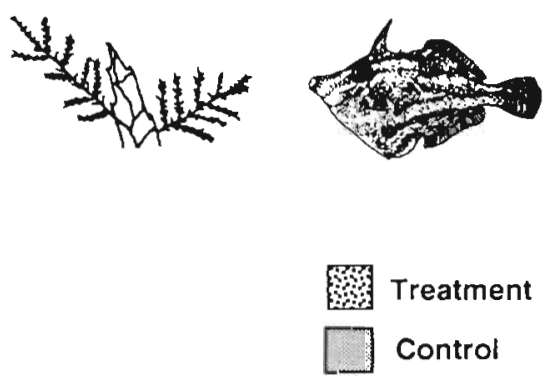

Fig. 6. Percentage of treatment and control artificial food pellets consumed by filefish Monacanthus hispidus for the tridentatols isolated from Tridentata marginata growing on pelagic Sargassum. Letters to the left of each bar denote the specific tridentatol(s) used in each assay Analysis was by Fisher's exact test. * Signitıcant differences $(p<0.05)$ in consumption between control pellets and pellets treated with parkular compounds. $\mathrm{n}$ is given at the base of each bar

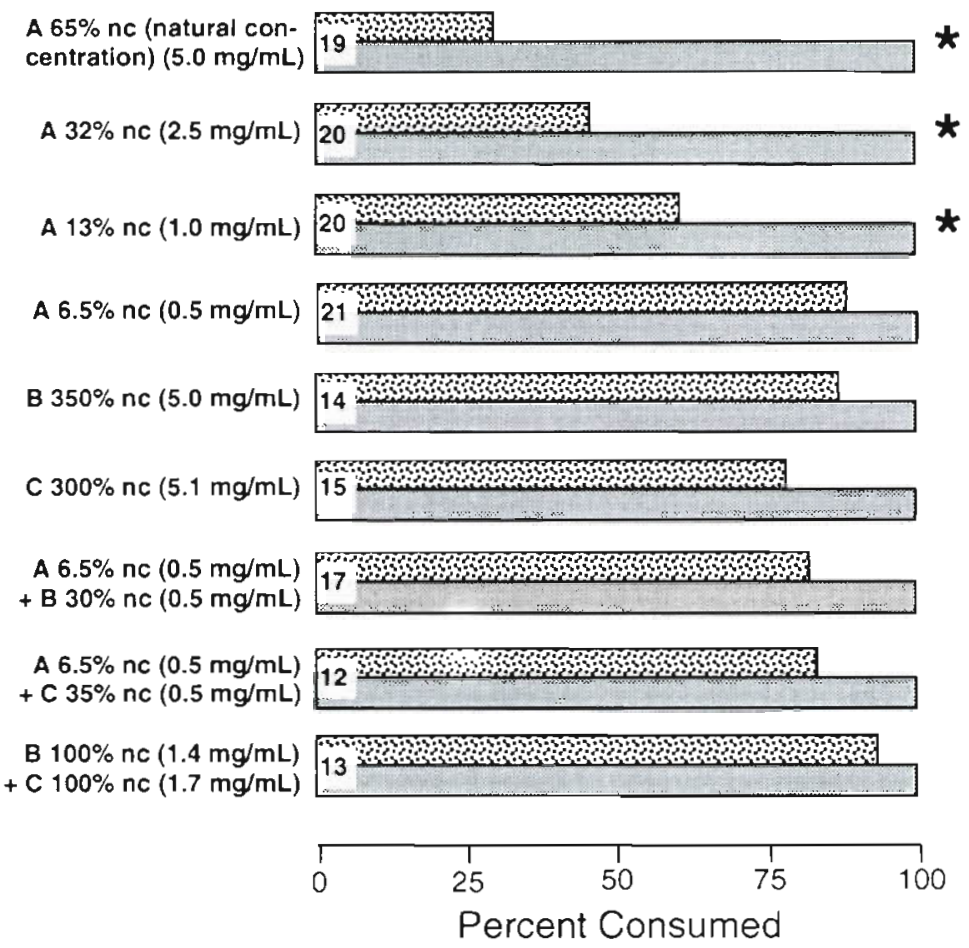

(Fig. 6). When $0.5 \mathrm{mg} \mathrm{ml}^{-1}$ of tridentatol $\mathrm{B}$ or $\mathrm{C}$ was combined with tridentatol $\mathrm{A}$ at $0.5 \mathrm{mg} \mathrm{ml}^{-1}$ to test for interactive effects on filefish feeding, these mixtures did not significantly diminish filefish feeding (Fig. 6) as tridentatol A alone did at $1.0 \mathrm{mg} \mathrm{ml}^{-1}$ (Fig. 6). Additionally, tridentatols $B$ and $C$ combined together at their natural concentrations did not significantly decrease fish feeding (Fig. 6)

Tridentatol $\mathrm{A}$, at $6.7 \mathrm{mg} \mathrm{m} \mathrm{m}^{-1}$ of hydroud tissue, was also the major secondary metabolite that we found in the lipid-soluble extract from benthic populations of Tridentata marginata. Benthic T. marginata, however, contained the novel metabolite tridentatol D, but not B or C. Tridentatol A extracted from benthic $T$ marginata significantly reduced filefish feeding $(-85 \%, \mathrm{p}=$
0.0003 , Fisher's exact test), accounting for all of the deterrence of the lipophilic crude extract (Fig. 7) Tridentatol D isolated from a given volume of hydroid tissue and combined with the same volume of squid paste had no effect on fllefish feeding (Flg. 7). We have been unable to isolate enough tridentatol D to use HPLC methods to accurately determine its natural concentration in the hydrold.

\section{UV-absorption spectra for the tridentatols}

Although only tridentatol A deterred fllefish feeding. all tridentatols examined ( $A$ to $D$ ) absorbed both UV-B (280 to $320 \mathrm{~nm})$ and UV-A (320 to $400 \mathrm{~nm}$ ) radiation

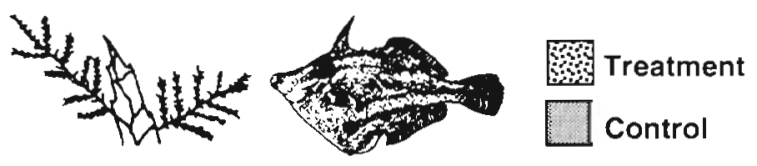

Fig. 7. Percentage of treatment and control artıficial food pellets consumed by filefish Monacanthus hispidus for the tridentatols isolated from benthic populations of Tridentata marginata. Analysis was by Fisher's exact test. * Significant differences $(p<0.05)$ in consumption between control pellets and pellets treated with particular compounds. $\mathrm{n}$ is given at the base of each bar

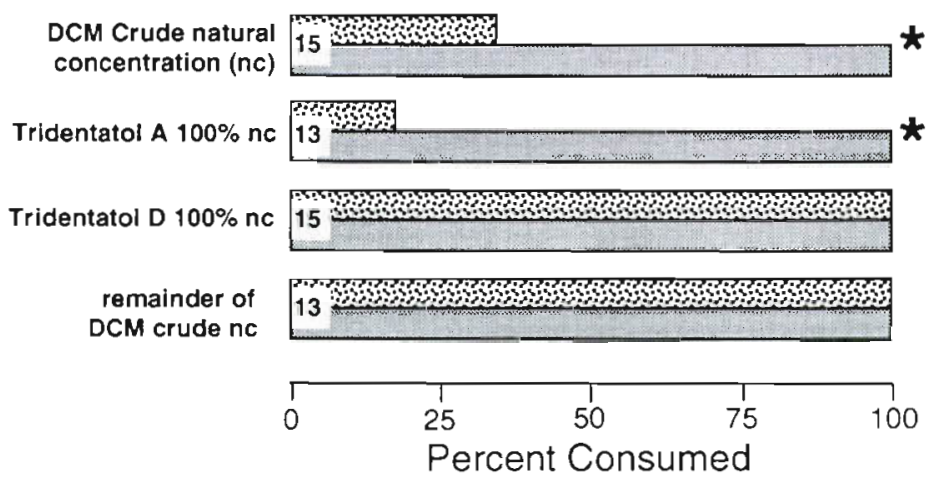




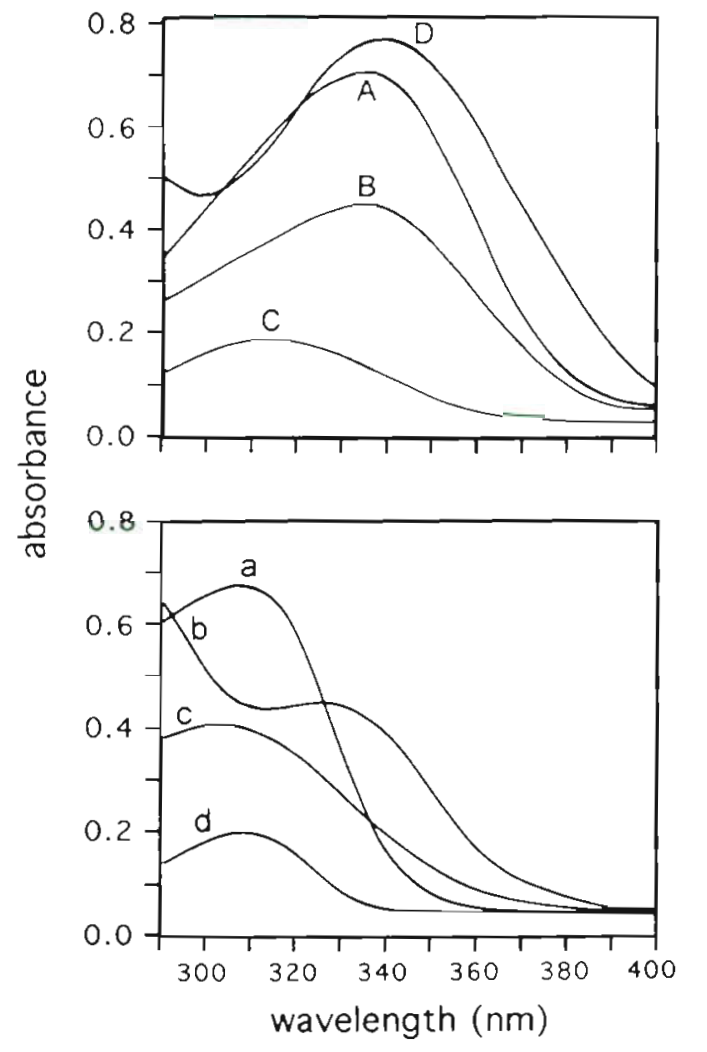

Fig. 8. UV spectra (290 to $400 \mathrm{~nm}$ ) of tridentatols A to D (top panel), and of the 4 'active ingredients' from Coppertone ${ }^{(*)}$ SPF 45 sunscreen lotion (bottom panel): octyl methoxy-cinnamate (a), benzophenone (b), octocrylene (c), and octyl salicylate (d). All spectra were recorded at a concentration of $0.01 \mathrm{mg} \mathrm{ml}^{-1}$ in methanol

(Fig. 8, top panel). Tridentatols A to D exhibited absorption maxima at $337,332,313$, and $342 \mathrm{~nm}$, respectively. Calculated molar extinction coefficients (ع) for tridentatols $\mathrm{A}$ to $\mathrm{C}$ were 18000,11000 , and 3000 , respectively, indicating that among these 3 metabolites tridentatol $A$ has the greatest UV-absorbing power per molecule. However, per unit mass, tridentatol D has the highest and broadest UV-absorbing potential (Fig. 8, top panel). No water-soluble compounds in Tridentata marginata absorbed UV radiation above $290 \mathrm{~nm}$. The 4 'active ingredients' in Coppertone ${ }^{*}$ SPF 45 sunscreen exhibited absorption maxima in the solar UV region at 305, 307, 310, and $323 \mathrm{~nm}$ (Fig. 8 , bottom panel). Comparison of their absorption intensity at $\lambda_{\max }$ with those of tridentatols $A$ to $D$ showed that, on a per unit mass basis, the tridentatols had equal or greater UV-absorbing power (Fig. 8, top panel vs bottom panel). Additionally, the tridentatols' UV absorptions cover the entire UV-B portion of the solar spectrum and much more of the UV-A spectrum than the commercial sunscreens.

\section{DISCUSSION}

Filefish feeding on 4 morphologically similar hydroids clearly differed, with Tridentata marginata being significantly less palatable than the 3 other species (Figs. 2 to 4). Skeletal material and nematocysts are unlikely to contribute to the low preference of $T$ marginata because at least 2 of the preferred hydroids (Aglaophenia latecarinata and $T$ turbinata) are similar morphologically (size, shape, composition of exoskeleton) to T. marginata, and at least 1 of the heavily consumed hydroids (Clytia noliformis) possesses microbasic mastigiophores (Ostman et al. 1987), a type of nematocyst that may be used in defense (Wellington 1980). Thus, the low palatability of $T$ marginata relative to the other 3 species is most likely due to its potent chemical defense (Figs. $5 \& 6$ ).

Tridentata marginata produces several structurally related compounds, but only tridentatol A significantly reduced filefish feeding, and functioned effectively as a feeding deterrent at levels well below its natural volumetric concentration (Fig. 6). Interactive effects among the tridentatols were not evident (Fig. 6). Additionally, results of our feeding assays with tridentatols $A$ and $B$ clearly demonstrated the often rigid relationship between compound structure and biological activity. These 2 compounds differ only in the conformation of the side-chain carbon-carbon double bond (Fig. 1), yet tridentatol $\mathrm{A}$ is a potent feeding deterrent while tridentatol $B$ has no apparent effect on filefish feeding (Fig. 6)

Given that the energetic investment of producing a compound comprising roughly $5 \%$ of its dry mass is likely to be high, it is unclear why Tridentata marginata should maintain tridentatol $\mathrm{A}$ at a level well above that needed to deter feeding by filefish. Although we assayed for chemical defenses using a hydroid-consuming fish that commonly co-occurs at high densities with $T$. marginata, other potential hydroid predators may be deterred only at compound concentrations well above that needed to deter filefish. However, at least on pelagic Sargassum, filefish appear to be the most abundant small predator, and other common predators such as shrimps and crabs do not consume hydroids in significant quantities (Fig 2). Additionally, we tested compounds for effects on wellfed predators, but hungry predators can be less selective (Cronin \& Hay 1996) and may be deterred only by higher levels of a chemical defense.

Alternatively, some secondary metabolites are known to play multiple roles that are ecologically important (Schmitt et al. 1995), and the amount of compound needed to adequately perform one function may differ greatly from that required for another. Living at the ocean surface exposes Sargassum and 
attached epiphytes to high levels of solar UV radiation, which is known to have detrimental effects on many marine plants and animals (Jokeil 1980, Wood 1987. Gleason \& Wellington 1993, Larkum \& Wood 1993). Even species inhabiting environments commonly exposed to high levels of solar UV radiation may grow more rapidly when shaded from UV (Jokeil \& York 1982). Because the tridentatols broadly absorb both UV-A and UV-B (Fig. 8, top panel), and they occur at such high concentrations, these compounds may effectively shield Tridentata marginata from potentially damaging levels of solar UV In fact, the tridentatols absorb solar UV radiation as well or better than the 4 UV-absorbing compounds in a popular sunscreen lotion (Fig. 8, bottom panel). The UV-absorbing properties of the tridentatols also compare well with those of the mycosporin-like amino acids (MAAs), a class of naturally occurring UV-absorbing metabolites proposed to function as sunscreens in many marine plants and animals (Dunlap \& Chalker 1986, Dunlap et al. 1986, Karentz et al. 1991. Garcia-Pichel et al. 1993, Karentz 1994). Because the water-soluble portion of T. marginata extract showed no UV activity above $290 \mathrm{~nm}$, MAAs apparently do not occur in this species, and the tridentatols may be its only chemical means of UV protection. Although the tridentatols have slightly lower UV-absorbing power than most MAAs, the tridentatols' absorptions cover much more of the UV spectrum, and they occur at much higher natural concentrations than the MAAs. Even though only tridentatol $A$ deters filefish feeding, all the tridentatols could provide protection against high UV levels.

The high densities of filefish we recorded on clumps of pelagic Sargassum, and the fact that they readily consume several species of hydroids (Figs. 2 to 4), suggest that these predators could have a large impact on the structure of the epiphytic community on pelagic Sargassum. Despite this, the hydroid species preferred by filefish (Clytia noliformis, Aglaophenia latecarinata, and Tridentata turbinata) are more abundant than $T$. marginata which is chemically defended from predation by filefish (Table 1). How, then, do these palatable hydroids persist within the predator-dense Sargassum habitat, and why is the hydroid fauna not dominated by unpalatable species? Although it is possible that filefish do not prey heavily on hydroids when other prey such as small crustaceans are available, filefish gut analyses do not support this hypothesis. Hydroids are consistently found in the guts of filefish taken from pelagic Sargassum, while other prey occur only sporadically (Dooley 1972).

Palatable species may persist if the density of predators is variable in space or time. Although not adequately documented, if predator densities are higher under larger patches of Sargassum, winds or currents that periodically aggregate Sargassum in rows or mats along frontal boundaries (Stommel 1965) or in windrows (Faller \& Woodcock 1964) could alter the density of Sargassum-associated consumers on individual patches over time scales as short as minutes to hours. On a larger scale, Gulf Stream rings move water masses between the continental shelf, Gulf Stream, and Sargasso Sea, facilitating the exchange of biota between geographically distant sites over periods of weeks to months (Ring Group 1981). Juvenile filefish are much more abundant on the continental shelf than in the Sargasso Sea (Fine 1970. Stoner \& Greening 1984), and Sargassum epiphytes may be exposed to variable predation regimes as their host-plants are moved between these areas. If there are trade-offs between resistance to predators and growth rates of hydroids, as has been demonstrated for marine algae (e.g. Lubchenco \& Gaines 1981, Hay 1985, Lewis 1986, Estes \& Steinberg 1988), temporal variability in predation pressure may account for the co-occurrence of both palatable and defended hydroids. Present efforts to investigate these hypotheses focus on documenting spatial and temporal variations in predator and prey abundance, and the persistence and growth rates of low- and high-preference hydroid species at experimentally manipulated predator densities.

Acknowledgements. Funding was provided by a grant from the Cooperative Institute for Fisheries Oceanography (CIFONOAA) to C. H. Peterson, R. A. Luettich, N.L., and M. E. Hay, NSF grant OCE 95-29784 to M. E. Hay, and an NSF graduate fellowship to J.J.S. Ship time and support on the RV 'Elusive' was provided by NOAA/NURC at the University of North Carolina at Wilmington. Comments by M. Hay, S. Bullard, M. Deal, and several anonymous reviewers improved previous drafts of the manuscript. Dale Calder of the Royal Ontario Museurn is gratefully acknowledged for identifying the hydroids.

\section{LITERATURE CITED}

Berry FH, Vogele LE (1961) Filefishes (Monocanthidae) of the Western North Atlantic. US Fish Wildl Serv Fish Bull 61:61-109

Bortone SA, Hastings PA, Collard SB (1977) The pelagic Sargassum icthyofauna of the eastern Gulf of Mexico. NE Gulf Sci 1:60-67

Bouillon J (1985) Essai de classification des hydropolypeshydromeduses (Hydrozoa-Cnidaria). Indo-Malayan Zool $1: 29-243$

Butler JN, Morris BF. Cadwaller J, Stoner AW (1983) Studies of Sargassum and the Sargassum community. Bermuda Biol Sta Spec Publ 22:1-85

Calder DR (1991) Shallow-water hydroids of Bermuda. The Thecatae, exclusive of Plumulariodea. Roy Ont Mus Life Sci Contrib 154

Calder DR (1993) Local distribution and biogeography of the Hydroids (Cnidaria) of Bermuda. Caribb J Sci 29:61-74 
Calder DR (1995) Hydroid assemblages on holopelagic Sargassum from the Sargasso Sea at Bermuda. Bull Mar Sci $56: 537-546$

Conover WJ (1980) Practical nonparametric statistics, 2nd edn. John Wiley and Sons, New York

Coston-Clements L, Seltle LR, Hoss DE, Cross FA (1991) Ut1lization of the Sargassum habitat by marine invertebrates and vertebrates-a review. NOAA Tech Mem NMFS. SEFSC-296

Cronin GC, Hay ME (1996) Susceptibiluty to herbivores depends on the recent history of both the plant and antmal. Ecology 77:1531-1544

Dethier MN, Graham ES, Cohen S, Tear LM (1993) Visual versus random-point percent cover estimations: 'objective' is not always better. Mar Ecol Prog Ser 96:93-100

Dooley JK (1972) Fishes associated with the pelagic Sargassum complex, with a discussion of the Sargassum community. Contrib Mar Sci 16:1-32

Dunlap WC, Chalker BE (1986) Identification and quantification of near UV absorbing compounds (S-320) in a hermatypic scleractinian. Coral Reefs 5:155-159

Dunlap WC, Chalker BE, Olvier JK (1986) Bathymetric adaptations of reef-building corals at Davies Reef, Great Barreer Reef, Australia. III. UV-B absorbing compounds. J Exp Mar Biol Ecol 104:239-248

Estes JA, Steinberg PD (1988) Predation, herbivory, and kelp evolution. Paleobiology $14: 19-36$

Faller AJ, Woodcock AH (1964) The spacing of windrows of Sargassum in the ocean. J Mar Res 22:22-29

Fine ML (1970) Faunal varlation on pelagic Sargassum. Mar Biol $7: 112-122$

Garcia-Pichel F, Wingrad CE, Castenholz RW (1993) Evidence regarding the UV sunscreen role of mycosporinlike compounds in the cyanobacterum Gleocapsa sp. Appl Environ Microbiol 59:170-176

Gleason DF, Wellington GM (1993) Ultraviolet radiation and coral bleaching. Nature 365:836-838

Hacker SD, Madin LP (199i) Why habitat architecture and. color are important to shrimps living in pelagic Sargassum: use of camouflage and plant-part mimicry. Mar Ecol Prog Ser 70:143-155

Hay ME (1985) Spatial patterns of herbivore impact and their importance in maintaining algal species richness. Proc 5th Int Coral Reef Congr 4:29-34

Hay ME (1996) Marine chemical ecology: what is known and what is next. J Exp Mar Biol Ecol 200:103- 134

Hay ME, Fenical W (1996) Chemical ecology and marme biodiversity: insight and products from the sea. Oceanography $9: 10-20$

Jokeil PL (1980) Solar ultraviolet radiation and coral reef epifauna. Science 207:1069-1071

Jokeil PL, York RH (1982) Solar ultraviolet photobiology of the reef coral Pocillopora damicornis and symbiotic zooxanthellae. Bull Mar Scl 32:301-315

Karentz D (1994) Ultraviolet tolerance mechanisms in Antarctıc marne organisms. In: Weiler CS, Penhale PA (eds) Ultraviolet radiation in Antarctica: measurements and biological effects. Antarct Res Ser 62:93-110

Karentz D, McEuen FS, Land MC, Dunlap WC (1991) Survey of mycosporin-luke amino acid compounds in Antarctic

This article was presented by Joseph Pawlik (Senior Editorial Advisor). Wilmington, North Carolina, USA. marine organisms: potentual protection from ultraviolet exposure Mar Biol 108:157-166

Larkum AWD, Wood WF (1993) The effect of UV-B radıation on photosynthesıs and respiration of phytoplankton, benthic macroalgae, and seagrasses. Photosynth Res 36:17-23

Lewis SM (1986) The role of herbivorous fishes in the organization of a Caribbean reef community. Ecol Monogr 56 . $183-200$

Lindquist N, Lobkovsky E, Clardy J (1996) Tridentatols A-C, novel natural products of the marine hydrold Tridentata marginata. Tetrahedron Lett 379131-9134

Lubchenco J, Gaines SJ (1981) A unitied approach to plantherbivore interactions: I. Population and communities. Annu Rev Ecol Syst 12:405-437

Morris BF, Mogelberg DD (1973) Identification manual to the pelagic Sargassum fauna. Bermuda Biol Sta Spec Publ 11: $1-63$

Niermann U (1986) Distribution of Sargassum natans and some of its epibionts in the Sargasso sea. Helgoländer Meeresunters 40:343-353

Ostman C. Piraino S, Roca I (1987) Nematocyst comparisons between some Mediterranean and Scandinavian campanularids (Cnidaria, Hydrozoa). In: Boullon J, Boero F, Clocogna F, Cornelius PFS (eds) Modern trends in the systematics, ecology, and evolution of hydrolds and hydromedusae. Oxford University Press, Oxford, p 299-311

Parr AE (1939) Quantitative observations on the pelagic Sargassum vegetation of the western North Atlantic. Bull Bingham Oceanogr Coll 6:1-94

Paul VJ (1992) Ecological roles of marine natural products Cornell University, Ithaca, NY

Pawlik JR (1993) Marine invertebrate chemical defenses Chem Rev 93:1911-1922

Peterson CH, Renaud PE (1989) Analysis of feeding preference experiments. Oecologia 80:82-86

Ring Group (1981) Gulf Stream cold-core rings: their physics, chemistry, and biology. Science 212:1091-1100

Schmilt TM, Hay ME, Lindquist N (1995) Constraints on chemically mediated co-evolution: multiple functsons for seaweed secondary metabolites. Ecology 76:107-123

Settle LR (1993) Spatial and temporal variability in the distr1bution and abundance of larval and juvenile fishes associated with pelagic Sargassum. MSc thesis, Univ North Carolina, Wilmington

Sokal RR, Rohlf FJ (1981) Biometry, 2nd edn. WH Freeman, New York

Stommel H (1965) The Gulf Stream. Univ Californa Press, Berkeley

Stoner AW, Greening, HS (1984) Geographic variation in the macrofaunal associates of pelagic Sargassum and some biogeographic implications. Mar Ecol Prog Ser 20:185-192

Weis JS (1968) Fauna associated with pelagic Sargassum in the Gulf Stream. Am Midl Nat 80:554-558

Wellington GM (1980) Reversal of digestive interactıons between Pacific reef corals: mediation by sweeper tentacles. Oecologia 47:340-343

Wood WF (1987) Effect of solar ultra-violet radiation on the kelp Ecklonia radıata. Mar Biol 96:143-150

Zar JH (1984) Biostatıstical analysıs, 2nd edn. Prentice-Hall, Englewood Cliffs, NJ

Manuscmpt received: March 17, 1997

Revised version accepted: June 6, 1997 